\title{
The Influence of Classification on World View and Epistemology
}

\author{
Gholamreza Fadaie \\ Faculty of Psychology \& Education, University of Tehran, Iran
}

\author{
ghfadaie@ut.ac.ir
}

\begin{abstract}
Worldview as a kind of man's look towards the world of reality has a severe influence on his classification of knowledge. In other words one may see in classification of knowledge the unity as well as plurality. This article deals with the fact that how classification takes place in man's epistemological process. Perception and epistemology are mentioned as the key points here. Philosophers are usually classifiers and their point of views forms the way they classify things and concepts. Relationship and how one looks at it in shaping the classification scheme is critical. The classifications which have been introduced up to now have had several models. They represent the kind of looking at, or point of view of their founders to the world. Aristotle, as a philosopher as well as an encyclopedist, is one of the great founders of knowledge classification. Afterwards the Islamic scholars followed him while some few rejected his model and made some new ones. If we divide all classifications according to their roots we may define them as human based classification, theology based classification, knowledge based classification, materialistic based classification such as Britannica's classification, and fact based classification. Tow broad approaches have been defined in this article: static and dynamic. The static approach refers to the traditional approaches and the dynamic one refers to the eight way of looking toward objects in order to realize them. The structure of classification has had its influence on epistemology, too. If the first cut on knowledge tree is fully defined, the branches would usually be consistent with it.
\end{abstract}

Key words: Worldview. Classification. Categorization. Human perception. Epistemology.

\section{Introduction}

The way of looking at the world of reality and categorization/ classification is inter- dependent. That is by looking at the classification scheme one can find out the point of view of the classifier. Kawsnik (1999) stated that classification was a kind of looking at things. The categorization/ classification are like ontology and epistemology that are inter-dependent too. As with Aristotle we may define that his categories are in ontological domain and classification in his epistemological one. Bakar says (1999): "the base of ontology is to define the chain of existence, which

Material published as part of this publication, either on-line or in print, is copyrighted by the Informing Science Institute. Permission to make digital or paper copy of part or all of these works for personal or classroom use is granted without fee provided that the copies are not made or distributed for profit or commercial advantage AND that copies 1) bear this notice in full and 2) give the full citation on the first page. It is permissible to abstract these works so long as credit is given. To copy in all other cases or to republish or to post on a server or to redistribute to lists requires specific permission and payment of a fee. Contact Publisher@InformingScience.org to request redistribution permission.
Farabi (260-339), one of the greatest

Islamic scholars stated it as the chain of existed". Hjørland and Nicolaisen (2005, p. 1) also state that the ontology refers to existence or being and Metaphysics is much related to ontology. They mentioned that the relation between the metaphysics and ontology got a bad reputation because of the bad use of positivism. Karl Popper, too, in his three world tries to emphasize on ontol- 
ogy (Brooks, 1980 in Hjørland and Nicolaisen, 2005).

Discussing on categorization/classification we have to refer to the concept of universal. Universal is a concept that all philosophers have paid their attention to it, because it is said that it is the basis of our knowledge, and epistemology takes place when universal comes to being. Hjørland and Nicolaisen $(2005$, p. 1) state that "epistemology is a philosophical sub discipline concerned with the nature, sources and limits of knowledge." Hjørland (2006, p. 5) describing library and Information science, talks of Meta theories and the need for philosophy of science in it. Budd (2001, p. 256) describing some scholars' view point on information seeking emphasizes "that information seeking is defined as the action of individuals who consciously search for, or ask about, content that may be relevant to the individuals' needs."

This article tries to locate the categorization / classification as a function in perception process. It also tries to explain that categorization/classification occurs before the concept of universal takes place.

\section{Universal}

The universal is supposed to be the basis for human knowledge. It also emphasizes that afterward, when the classification scheme comes to being, it affects the way of looking at the world of reality and in somehow forms the thinking process.

Philosophers have talked over universals through the ages up to now but I argue that they have not explained the role of categorization/ classification in this area clearly. After Greek philosophers, such as Aristotle (384-322 B.C.), most of the Islamic philosophers followed them. In modern Western philosophy, we may mention Hegel (1770-1831), who claimed that his philosophy is the combination of all his precedents (Stace, 1923). He states that the ontological categorizations are concepts that the simple mind of man uses to recognize the world. To him it is the category of being and the category of notion. Other categories of being, to him, are different aspects of quantity, quality and measurement. To know these is the result of man's simple effort to realize the world. Then Stace describing Hegel's view continues:

In higher level, we reach to scientific approach. What distinguishes the simple categorization from scientific classification is that the science classifies the objects and through this mind realizes the many different characteristics in the world.

To Hegel, what is defined in classification is not the real entity, but thought.

\section{How Categorization/Classification Takes Place}

Although there may be some slight differences between categorization and classification (Jacob, 2004) here, I use both terms and it may not harm my reasoning here. Their differences are somehow like the difference between ontology and epistemology. Category is defined as ultimate class and highest genera of entities (Meiland, 1995 in Hjørland and Nicolaisen 2005, 1). And classification, in general as well as in library applications, is defined as putting the most similar things adjacent to each other. Krishnan Kumar (1979, p. 1) says that the "classification is a process of grouping. It involves putting together like entities and separating unlike entities." What is important in this area is whether or not we can attain knowledge (or science) without having any classification activity. It is evident that from the earliest moment of life, when one encounters reality, he/she receives images, forms concepts, names them, creates definitions for them, and stores them in his/ her memory. But for recalling them, in actual recognition one must refer to the places, physically or mentally where they have been put before. It is easy to search when the things and concepts are few, but when the number and variety of things and concepts increase, one has to cluster them and put them in distinguished or coded places in order to retrieve them 
easily and correctly. So, this is the reason why we must accept that from the very beginning of our lives when we encounter the reality, we should organize our memory and therefore develop a sort of classification. This classification may be affected by the extent of our information and mostly by our way of looking at the world. To explain more, for example, when we want to mention blackness, or whiteness, as universals it is not possible unless we categorize/classify some similar things as blacks and whites. Then we derive the concepts of blackness and whiteness from them. We must consider that the ordinary classification by people for current use may differ from the scientific classification. But the process in both applications does not differ. As in ordinary classification one has some purpose for application, in scientific classification which tends to all subjects it inevitably shows the classifiers' philosophy or point of view. Thus the advanced classification schemes have been made under the influence of philosophical or scientific approach of the time when their founders have made them.

\section{Perception and Epistemology}

As scientific classification usually comes after the formation of concept of universal in the mind, so it is suitable to reconsider the process of perception and epistemology.

It is obvious that the basis of our knowledge is one's self knowledge. And the real perception is the presence of one near his/her soul. Here, I argue that the perception is an activity of soul, not mind and the mind is one of the soul's faculties which work under its auspicious. Mulla Sadra (1050/ 1621) one of eminent Islamic philosopher states that the human soul in its unity is all its faculties. Although in Christianity we may find such ideas, recent Western thinkers changed or confused the soul with mind. To some of them soul is nothing but mind. Here I think that the knowledge takes place just when the object encounters the soul, not when it comes to the mind. Mind is subordinate to the soul. To explain more, the soul in its encountering with the world of reality has double functions at a time; first the mere presence of the object in front of the soul is equal to real (not mental) perception. Second, and immediately through senses the characteristics of the object is pictured on mind and by the presence of this picture, soul, not mind perceives mental concept in the same way that it perceives the real object. Then mind sends them all to the memory. Mind under the auspicious of soul and with supervision of wisdom (or you may call it intelligence), in order to retrieve the concepts one has already perceived, has to name, and/or classify them according to their characteristics, functionalities and/ or activities. So, categorization / classification are the essential and first step for organization of one's memory. Because, every one in order to increase her/his knowledge tries to find out, discover and make adventure in the world. In order to regard them totally, locate them specifically and, retrieve them properly and easily, and to communicate with others one has to collect all similar things and put them in groups. The function of soul in regarding the groups is in the same way as for individual object. These groups are the basis of categorization / classification paradigm which make universals. By universals we can retrieve our knowledge and communicate with others.

As shown in Figure 1, perception is the function of soul in a double ways (Fadaie, 1384/2006). The mind does its duty only as mental imagination which depends on real perception. In other words, all faculties (Meshkat al dini, 1364) sum up in soul and as Mill (Cappelstone, 1380) states: "in analysis of the concept of mind, one must regard to the principality of soul." Then it does not make difference how we call it; we may call it rational soul as Fakhr- Razi( $6^{\text {th }}$ century of Higri) stated or name it common sense as Avicenna (270-428 h.) and Khawja Nasir (6 $6^{\text {th }}$ c. of h.) talked about (Hasani, 1373/ 1994). In Figure 1 the certainty of real perception of world of reality which is showed by bold line is considerable. Up to here all things take place in ontological domain. From here on, we enter the realm of epistemology. In epistemological domain we depend on reality again. That is, for explaining the object in its pure essence, its application or activities, one must group all similar ones and then allocate them a name or adjective. This means that in order 
to enter into the realm of universals we have to group the similar objects in the real world. That is, although universals are mental they are dependant on reality, and similar grouped objects. Then by making universals in epistemological domain they come to being afterwards. It is from here that the classifiers' philosophy or their point of view influences on one's classification.

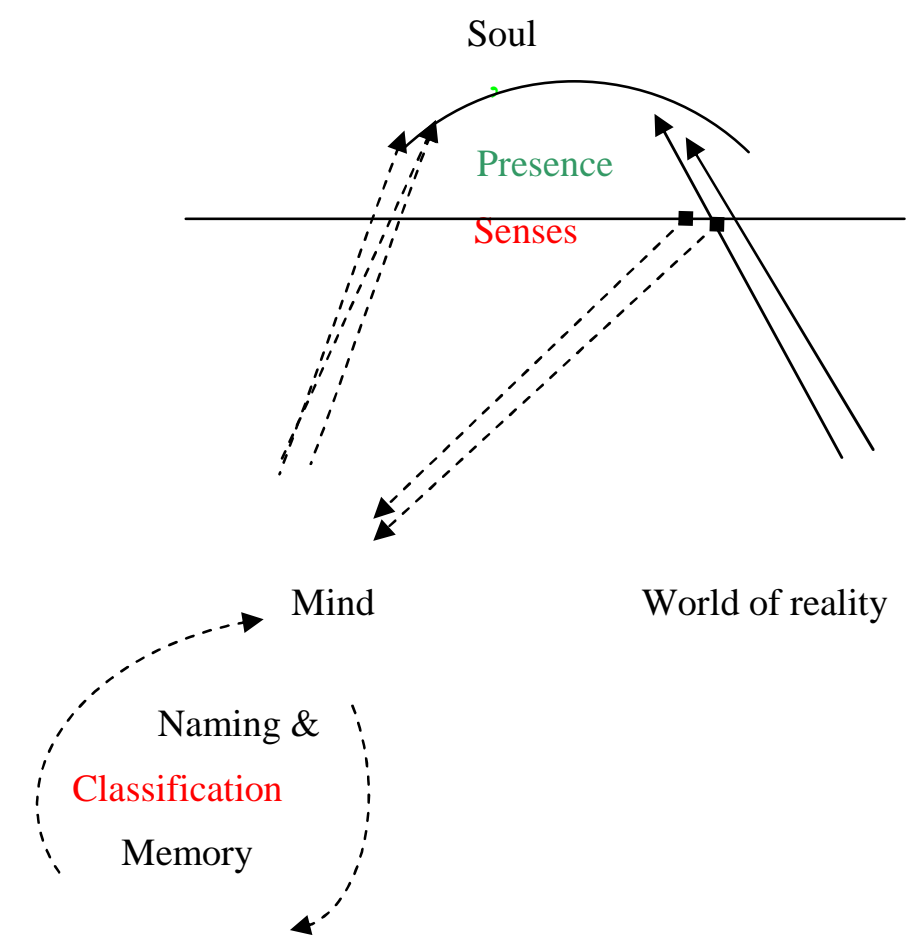

Figure 1- Perception of the world of reality as well as mental existence

\section{Philosophers as Classifiers}

It is evident; as we see in the Figure 1 that the process of categorization / classification of things and concepts are the every body's need in ordinary life, as well as in his / her special profession. In high level and in general, the most advocators of categorization / classification are philosophers, encyclopedists and librarians, respectively (Fadaie, 2004). After these three, the biologists are the most users, because they need to classify the varieties of bio-existed creatures. Hence, Aristotle is regarded as the first founder and the father of classification of knowledge. Al- Farabi, known as the Second Teacher although followed Aristotle made some new amendment to his scheme. Ghazzali (450-505 h.), one of the Islamic scholars has introduced several kinds of classifications, at least in three of his books named: Mishkat al anvar, al risalat al ladoniyah, and Mizan al 'amal(Bakar,1999). In Western Europe, after the renaissance, we have some scholars such as Sir Francis Bacon (1562-1626), Auguste Comte (1798-1857), Herbert Spencer (1820-1903) and Andre Marie Ampere (1775-1836) as philosophers who made some classification schemes. Here I do not mention Dewey or Ranganathan because I do not enter in the realm of Library science specifically. Although facet analysis of Ranganathan is something in realm of category (Hjørland \& Nicolaisen 2005, p. 2). 


\section{The Role of Categorization / Classification}

As categorization and classification are the basic mental activities which take place in our very ordinary lives, then it is obvious that every body must have some notion of it. That is, as we live in the world of plurality then we have to bunch and group the objects or concepts in order to be able to refer to and apply them. Classification has a great role in education and learning process too (Anderson \& Krathwahl, 2001). Therefore, without it no change and development will take place. It is evident that the classification for current application is far from what must be permanent. As mentioned before, the philosophers are the main advocator or better to say creators of classifications schemes. They tried to put their works on the basis of reasons in order to be defendable over the ages. Here there may appear some differences in the various schemes and this is due to the different point of views or philosophies of the founders. Bakar (1999) in describing the three ways of classification of knowledge among three Islamic scholars: Farabi, Ghazzali, and Qutb al din Shirazi (634-711) states:

The three main bases in classification of knowledge to them are, methodological, ontological, and moral. These three bases deal with three basic aspects of sciences. That is; ontological basis with the subjects of sciences, methodological basis with the methods and the third one with teleological aspect of sciences.

Dahlberg (1992, pp. 187-188) points out that the organization (categorization \& classification) of knowledge throughout the history has been for the four main purposes:

(1) Knowledge representation

- Philosophical classification systems

- Education- oriented classification systems

(2) Knowledge utilization

- Encyclopedic classification systems

- Word classification systems

(3) Knowledge mediation

- Library- bibliographical classification systems

- Documentation classification systems

(4) Knowledge organization

- Science -oriented, economics, and administration oriented classification systems

- Information-systems oriented classification systems.

As shown in Dahlberg's division the purpose of knowledge manifestation for man to become aware about himself and the world outside is divided into four parts which all these aspects tells of one thing which is man's epistemology and understanding. Representation, utilization, mediation, and organization all are used to support man's knowing of the world. We can also define his approach as to organize knowledge by mediation for utilization to represent us the world of reality. But here one may ask how and from where one must begin. This nevertheless leads to the first point of view of the classifier (Kawsnik, 1999).

\section{The Ways of Classification}

The unity of knowledge, especially at the beginning is something over accepted (Challaye, 1378). This unity afterwards has to be put into branches. After Aristotle, the Islamic scholars have classified knowledge in many ways. Some of the most famous of them are as follows: theoretical and 
operational; for this world and the hereafter; rational and narrative; before Islamic era and after that; and so on. All indicate the point of views of their founders. For example, Ghazzali has four various (Bakar, 1999) categories for knowledge: theoretical and operational; presence and nonpresence, rational and religious, and individual and social obligations.

We must take into consideration that the classification is something equal to man's knowledge and as Challaye states (1378) "classification shows us the man's epistemological development and also helps us in education". Ampere (1775-1836) says: if a natural classification is used in educational programmes, the development in education takes place and understanding the sciences would be easier.

\section{Relationships}

Relationships among the phenomena are very important. Without which it is rather impossible to talk about anything. As for knowing things we have to divide, categorize, and classify and put them into branches. Therefore relationships among these branches are vital. More over some has asked if after entities there is any thing more important than relationships (Beans \&Greens, 2000). It is obvious that the epistemology comes when we compare objects with one another. And this is what we are obliged to do in the world of plurality. As in our usual perception of the world, we perceive them with all their characteristics but when we want to re use them or show them to others we have to define their internal and external relationships and put them in groups by categorization and classification. Therefore, if we want to talk about all phenomena, we should express our way of looking at the world outside.

\section{Kinds of Relationships and Their Impact on Classification of Knowledge}

As told before, relations are too many and it depends on the fact that from which angle one considers the objects. As far as we cannot discuss all relationships which is told to be more than 120 (Beans \& Greens, 2000), so here we talk about the most important ones. First cut (Kawsnik, 1999) means the first looking at the world by a scholar or scientist. This first look explains the very pure and clear attitude of a scientist toward the world. This first look or attitude shapes one's way of looking toward all phenomena which he/she encounters and wants to categorize or classify them. In the first contact with the world of reality we may define these relationships in two aspects: vertical and horizontal. Because, it seems that what we may encounter without any means are these two relationships. In the vertical relationship we suppose that every one understands the stretches in three dimensions (Koplestone, 1362). And in horizontal we suppose that the motion is the most obvious thing that is along with every phenomenon.

\section{A- Vertical relationships}

From this approach we consider the phenomena in linear way either from up to down or vise versa, which is called hierarchy. Among relationships, hierarchy is the most famous and most forceful relationship. Despite, some objection that (Mortimer, 1998) says that nowadays, with the development of science and technology, there is no chance to grasp the hierarchy, but still hierarchism is the most powerful relationships that the man has ever known. Mortimer states that now knowledge is as a circle, from where ever one begins that is the first point. It may be because of too many branches of science and not the full rejection of hierarchism?

\section{B- Horizontal relationship}

In horizontal approach the default is that all phenomena in the world of reality is with motion.

That is motion is the only sign of the life. Any creature which has a kind of living has a portion of 
motion with it. All philosophers and scholars believe in motion but the difference is on whether the motion is inside of the phenomena that is intrinsic, or it is something which comes from outside of it. For example, Mulla Sadra $(-1050 \mathrm{Hg}$.), one of the Islamic scholars believed in intrinsic motion.

In horizontal approach we can work on two ways: one which I may call it static and another dynamic. In static way as in traditional philosophical studies they first divide the phenomena into two categories: substance and accident; if somebody wants to study things he may have to define it first as substance or accident. The substance has some characteristics and the accident has some other ones and they may be opposite to, or different with each other. Or in recent Western era began by Descartes (1596-1650) and his followers the way of study changed and they mostly believed on man's experience. They ultimately thought that they do not need to go over nomenas and phenomena are enough to be studied. In positivistic view researchers had to break down things in order to study them. This kind of looking at the world finally brought up a severe opposition from post modernists (Gephart, 2005, p.1). But they could not define their theory and give a very clear perspective of what they wanted to state. It seems that they are fallen in a chaos and searching for a new way of study. Wallner\& Greiner (2006) stated that in modern Europe they changed from the importance of comprehensibility to the importance of success. They say although this was very interesting it seems to be very dangerous.

\section{Dynamic Approach}

As I mentioned before, here I am trying to define a new approach that I am calling it as a dynamic approach. In dynamic approach we study the phenomena as they are, and while they are taking their roles in the world of being as actions and interactions. In this way of looking we do not need to define things as substances and accidents although we do not reject them. Also there is no need to emphasize that all things must be experienced visually and physically. In the dynamic approach which, somehow can be called as operational logic (Challaye, 1378) too, we look at the phenomena as they are working in systems and sub-systems. These approaches, as far as I have searched has reached to eight. These are as follows:

\section{1- Phenomenal Approach}

In this approach we look at objects as real phenomena, which is dependent to something else in their creation. This approach usually takes place in the philosophical domain.

\section{2- Imaginary (Thought) Approach}

In this approach the problem is how we name or should name the objects. Here all the issues related to language and logics may be discussed. In other words the epistemological consideration is brought here.

\section{3- Structural Approach}

In this approach the structure of the phenomena are discussed. Such disciplines as physics, chemistry, biology, mineralogy and the like are discussed here.

\section{4- Behavioral Approach}

In this approach we discuss about the actions and transaction of all objects with one another especially in living creatures. Here such disciplines as psychology, sociology, communication and the like are discussed. 


\section{5-Continuing Approach}

As all creatures come to the world in order to continue their beings, so in some cases our approach is to study how the objects, especially living creatures try or must struggle to survive. In this case every living creature, especially human beings must try in two ways, one just for the continuation of its being, and second it must have some sort of destination it is going toward it. Here some disciplines such as medicine and related subjects, religious studies, economics and education may be discussed.

\section{6-Computational (Mathematical) Approach}

As all objects are in forms and numbers and we cannot find any individual things and as every thing are subject to change, there fore all things have to be considered from quantity or quality points of view. The importance of mathematics in epistemology reached to the point that Descartes (Challaye, 1378) wished and claimed that one day every thing could be studied just from mathematical point of view. Anyway, such disciplines as mathematics and arts may be placed here.

\section{7-Settlement Approach}

As every thing inevitably must occur in a place, time, and has some relationships to other things, so study from this point of view is of importance. Such disciplines as history and related topics, geography and astrology may be discussed here.

\section{8- Effective Approach}

There are many things in the world although we can not observe them visually they exist and we can study them by their effects. These effects may be divided in direct effect or indirect effect. Direct effect usually comes when the notion of cause and effect is discussed and may share with

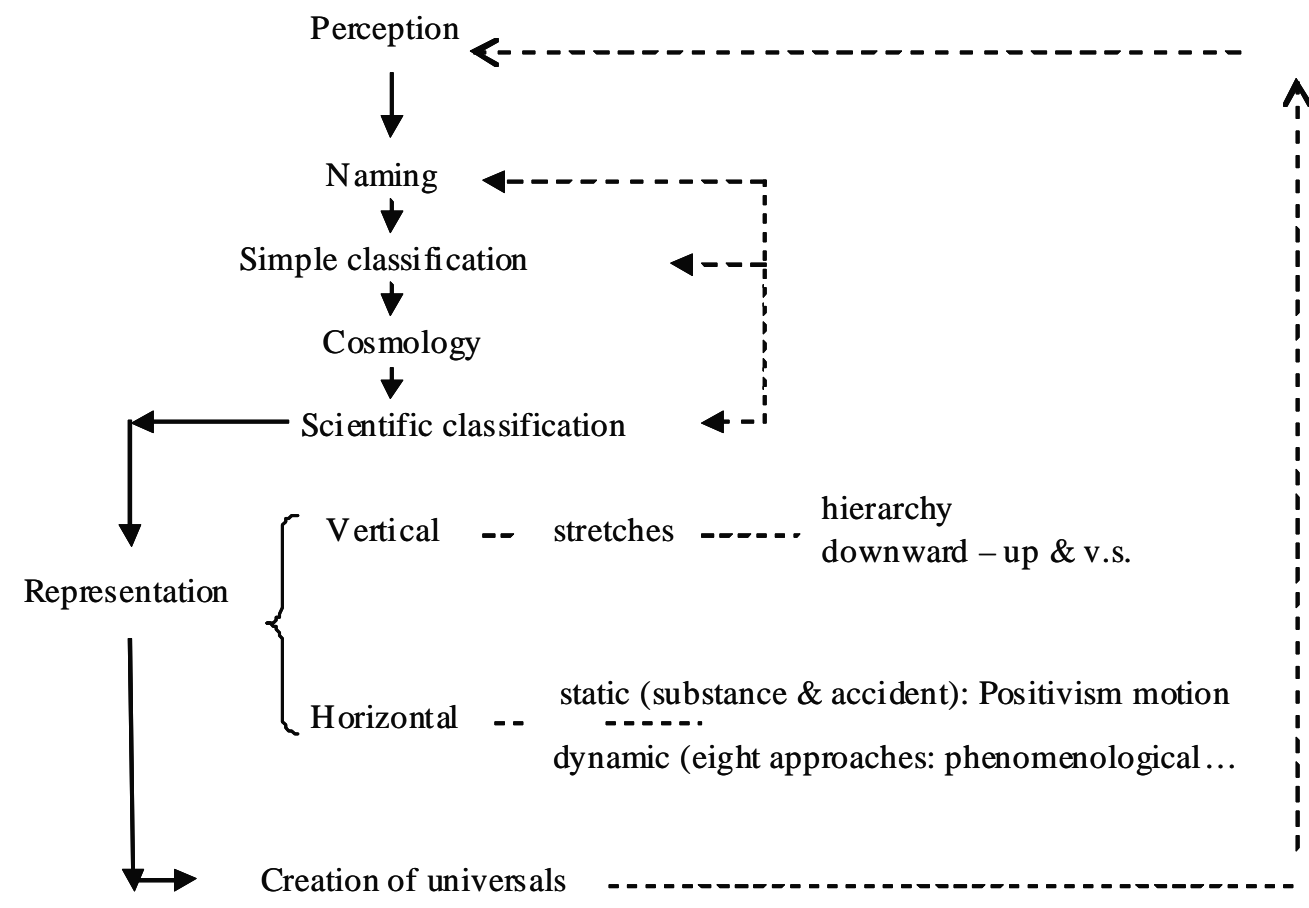

Figure2. The role of classification in perception, cosmology, universals 
the first approach but in indirect effect there may be many reasons for the creation or the activity of something which could be studied. Here disciplines such as literature, culture and civilization and interrelation of people or nations may be considered. The Figure 2 may have more.

As you see in the Figure 2, after perception of the real object by soul, the mind's function is to memorize what has already perceived. Here, we are not going to go through other internal faculties of soul such as imagination (Hasani, 1373), but we must know that all we perceived is the reflection of the real world, directly or indirectly. In this regard, and at this moment, to retrieve better what we have perceived we have to categorize or classify all things according to similar characteristics and /or activities which they have. The process of categorization / classification is real and not merely in our mind. This means that first by observation we categorize /classify then we extract (make) concepts from common similarities suitable to those groups classified. Here the statement related to Mutahari (-1358 h.), one of the recent late scholars seems to be odd. $\mathrm{He}$ stated (Nabavyan, 1382):

After knowing a thing or other kinds of that thing, the soul is gradually prepared to understand universals. That is, for example, when one sees a tree, his soul prepares to understand the universal. As when he understands himself by present knowledge, and then understands the universal concept of the soul.

Because when he states a tree, we should ask, how the concept of universal of tree has come to one's mind, in order to be able to compare an individual tree with this universal concept. Is it not after the real categorization or classification according to the similarities of the things, which then we named tree? If we had from everything, only one example and not more, was it necessary or possible to do such activities?

\section{Collective Approach}

Each of the eight approaches, as were shown briefly above, is indicating some characteristics of the phenomena from one aspect. From the point of a researcher if one aspect is more important and it is applicable for him, it is obvious that aspect is discussed more. And this is the reason that the first cut in universal classification is very important. If one looks at the world just from imaginary point of view, then the language and logic may be in the first level of importance. The linguists and logician may do so. But if the internal structure of the objects is more important to a researcher, he may define the objects according to the structures, as physicians, chemists and the like act so. Psychologists act in another way and so on.

If we compare this new approach with the old approaches we may find that here first all things or phenomena are observed or discussed in action or in the way they are doing their functions not in an isolated form. For example, in old Aristotelian way one may consider the substance or accident or discuss about time, space, motion, matter and the like separately which there is no end to such kind of discussions. Or in recent time, many positivist scholars believed that every thing in its isolated form must be studied or should be experienced and did not care the comprehensibility. To them, what is important is the success as mentioned by Wallner and Greiner (2006).

Second, in old methodologies the phenomena might be considered from one or more aspects which may be the core point of research and attention in that time; such as what were studied in ancient time, or in recent era by many different or contradicted ideologies and may have brought some proud ness for the scholars that they have discovered all problems. Here as every thing must be considered from at least eight points of views no one can claim that he has reached to the top point and must think that he is always in the way. Therefore there may bring some sort of cooperation among scholars to recognize the world of reality. We all know that in recent centuries many ideas have affected the minds and made them not to be able to concentrate carefully. For example Gephart states (2005, p.1): 
"Positivism has become a dominant institutional form in social research. Yet this dominance is increasingly challenged by critics from two alternative traditions - interpretive constructionism and critical postmodernism".

The point is this that in the phenomenological approach the answer to the questions such as "is something phenomenon or no", is always yes or no. In other approaches, we usually do not have this kind of answers. Other approaches are subjects to investigation. The scholars may discover all days some new things and the man may never reach to the end of his investigations. Thus, when a scientist begins to classify the knowledge, he shows and applies his unity-based approach to his classification. For example, Farabi (Bakar, 1999) in one of his scheme shows the hierarchy of the universe as God, angels, celestial bodies, and earthy things. Or Ampere (Challaye, 1378) divides the whole things in two big groups: one which studies the matter and the second which study the mind.

\section{Kinds of Classification of Knowledge}

Despite of the ordinary classification or applicable ones, there are some general classification schemes which imply the philosopher's point of view. His first cut is of great importance (Kawsnik, 1999). Islamic scholars have had some considerations (Tahanovi, 1967) on classification such as superiority, general and special, prerequisite and so on. Here I am not going to discuss the classification in full consideration. Only I am going to group them according to their first cuts and I believe that this first cut shows the philosophy or point of views of the founders considerably. But it should not be neglected that every classification scheme may be considered from one or several aspects. For example, the Aristotelian classification may be studied from methodology or subject point of view. Therefore, we can divide the classification of knowledge into two kinds: $A$ religious based classification and $B$ - non religious based classification.

The examples of the first are those such as Individual obligations and sufficient obligation of Ghazzali, or knowledge of this world and knowledge of the hereafter.

The non religious based classification may be divided as following:

\section{1-Thought (Reason) Based Classification}

According to this kind many scholars from East and West have thought the same. To me Aristotle's classification is basically the same as many Islamic scholars such as Avicenna. Hegel's classification is based on thought too.

\section{2- Education Based Classification}

As many classifiers have been teachers, so their classifications seem to be based on teaching and learning. They have begun from language and literature. The examples from this kind we may mention the classifications of Farabi, Qlqashandi, and Ibn-'Akfani. They began their classification from learning procedure.

\section{3- Time Based Classification}

Such as classification of Ibn- Nadim who classified all knowledge to pre-Islamic knowledge and Islamic knowledge.

\section{4- Experience Based Classification}

The example of this kind is the new classifications of Western scholars such as Ampere, August Comte (1798-1857) and others. They emphasize on experiment. 


\section{5- Material Based Classification}

The example of this kind of classification may be what Propedia in Encyclopedia Britannica has done. According to it all knowledge are divided in ten which begins from Matter and energy and then ends to human activities (Britannica, 1999), and

\section{6- Fact Based Classification}

This kind of classification to me refers to the new classification scheme which is called as Universal Binary classification. This classification tries to regard the objects as they appear in the world of reality: (All classification are more or less clear and there is no need for more description except the last one, which is a new one (Fadaie, 2004), and is only inspired from one of the Qur 'an 's verses which states:

We will show them Our Signs in the universe, and in their own selves, until it becomes manifest to them that this is the truth

This classification scheme is based on hierarchism and binary. As both principals are existed in the world of reality it is categorized as fact based classification. That is although inspired by the Holy Qur' an one can easily find the hierarchy which derives from the unity of the world. Also pair ness or symmetry is existed in all we get acquainted with. Although the symmetry may not be seen in the first glance it is quite evident after thinking of, and understanding the things. This scheme is called Universal Binary classification UBC. It means that every thing in the world may be found in pairs. The full article is published in Persian and Arabic in Majalle Daneshkade Adabyyat Daneshgah-e Tehran (Journal of faculty of Letters and Human Sciences) (1380/2001) and 'Afaq- al Hidarah al- Islamyah (a Biannual Journal on Horizons of Islamic Humanities) (1378/2002) respectively).

\section{The influence of classification on world view and epistemology}

If we have already accepted that the worldview of philosopher or any scholar engaged in classification is shown in his classification we must note that from the other side when the scheme is exposed and completed it will influence on the extension of the scheme. Besides those who follow the classification scheme as knowledge representation inevitably would follow the same philosophy or way of looking at the world of reality as did its founder. This means that organization is necessary but sometimes it shapes the mind and dictates others what to do and how to act. If some believed in a kind of classification it means that they believed in a kind of looking at the world of reality. It affects on epistemology too. To get rid of what already accepted, especially if it was learnt in childhood, is very difficult and takes time.

\section{Conclusion}

As Challaye (1378) stated the classification of knowledge is the aim of philosophy. And it helps us to organize our scientific thought. If a philosopher does not have a bright mind to organize the knowledge in a systematic way he not only cannot understand the universe but he cannot be considered as a philosopher. When we talk about the universals as the basic point for our epistemology we must know without going through categorization / classification it is impossible to reach it. The first cut is critical and decisive and it shows the kind of looking of the scholar at the world of reality. This makes the basis of his epistemology which in turn is based on the reality. As classification influences on the development of epistemology so scrutinizing from the very beginning is of high importance. We must not neglect the fact that the full study of something is to study it from all eight above mentioned approaches. Thus every approach is not only in opposite to the others but they all complete each others. Also nobody can claim that he has understood every thing. Accepting these approaches bring all scholars from different domains together to help, to 
listen, and to respect each other. It means that man is always on the way to promote his understanding from himself and the world.

\section{References}

Anderson, L. W., \& Krathwahl, D. R. (Eds.). (2001). A taxonomy for learning, teaching and assessing; A revision of Bloom's taxonomy of educational objectives. N.Y.: Longman.

Bakar, O. (1999). The history and philosophy of Islamic science. Texas: Islamic Texas Society.

Bean, C., \& Green, R. (2001). Relationships in the organization of knowledge. London: Kluwer Academic Publishers.

Budd, J. M. (2001). Information seeking in theory and practice: Rethinking public services in libraries. Reference \& User Services Quarterly, 40(3).

Challye, F. (1378/1999). Shenakht- Ravash...(Philosophy scientific...). (Yahya Mahdavi, Translated into Persian). Tehran: University of Tehran.

Dahlberg, I. (1992). The basis of new universal classification systems seen from philosophy of science point of view. In N. J. Williamson \& M. Hudon, Classification research for knowledge representation and organization (pp. 187-198). NY; London: Elsevier.

Fadaie, A. G. (2004). The new scheme in classification of knowledge. Cataloging and Classification Quarterly, 38(2).

Fadaie, A. G. (1384/2006). Tasavor va Tasdiq (Perception or assertion). Maqalat va Bar rasiha (Articles and considerations.) No. 78.

Gephart, R. (2005). Paradigm and research methods. Retrieved from http://www.aom.pace.edu/rmd/1999_RMD_Forum_Paradigm_Research_Meth...2005/08/31

Hasani, H. (1373/1994). Bar rasi ...(Survey and judgment on disputes between two Islamic philosophers: Khawja Nasir Toosi and Fakhr- Razi). Tehran: University of Tehran.

Hjørland, B. (2005). Library and information science and the philosophy of science. Journal of Documentation, 61(1), 5-10.

Hjørland, B., \& Nicolaisen, J. (2005). The epistemological lifeboat: Epistemology and philosophy of science for information scientists. Retrieved from http://www.db.dk/jni//ifeboat/Concepts/Ontology\%20\&\%20Metaphysicss.htm

Jacob, E. K. (2004). Classification and categorization. Library Trends, 52(3).

Kapelstone, F. (1362/1983). Tarikh... (The history of philosophy). (H. Amir A`lam, Translated into Persian). Tehran: Soroush.

Kwasnik, B. H. (1999). The role of classification in knowledge representation and discovery. Library Trends, 48(1), 22. In EBSCO host: Academic Search Elite.

Kumar, K. (1979). The theory of classification. New Delhi: Vikas Publishing House, PVT.

Meshkat al Dini, A. (1364/1985). Elm ...( What is knowledge?). Tehran: University of Tehran.

Mortimer, M. (1990). Knowledge becomes self conscious. Encyclopedia Britannica, Propeadia. New York: Encyclopedia Britannica.

Nabavyan, M. (1382). Mafahim...(The concept of universals). Ma 'refat Falsafi. 1(1\&2)

Stace, W. T.( 1355). Falsafeh Hegel (Hegel's philosophy). (Hamid 'Enayat, Translated into Persian) Tehran: Jeebi; Franklin. Vol. 1

Tahanovi, M. M. (1967, 1862). Kashshaf ...(Islamic technical term glossary). /calcatah, reprint in Tehran. 
Wallner, F. G. \& Greiner, K. (2006). Theoretical framework for research methodology. The new approach to science. In Proceedings of The First International Conference on Research Methodologies in Science, Engineering \& Technology. Tehran. Iran: University of Imam Hosein.

\section{Biography}

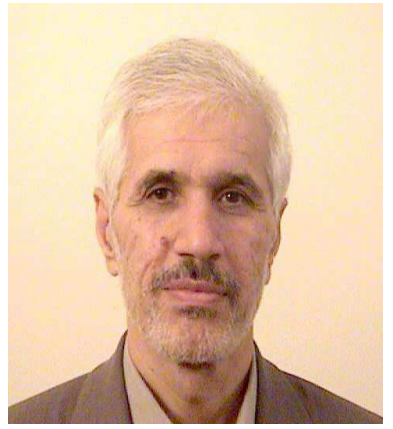

Gholamreza Fadaie, Ph.D in LIS, is associate professor in Faculty of Psychology \& Education, University of Tehran. Iran. He is 62 years old and has about 14 books and more than 30 articles in Persian. Also he has several articles in English and Arabic. Four of his English articles have been published in Cataloging and Classification journal in 2004 and 2005. He has some new idea about classification and philosophy of LIS. 